\title{
Vaccination strategies to conserve the endangered African wild dog (Lycaon pictus)
}

\author{
K.C. Prager ${ }^{\mathrm{a}, *}$, R. Woodroffe ${ }^{\mathrm{a}, \mathrm{b}}$, A. Cameron ${ }^{\mathrm{c}}$, D.T. Haydon ${ }^{\mathrm{c}}$ \\ ${ }^{a}$ Wildlife Health Center, University of California, One Shields Avenue, Davis, CA 95616, USA \\ ${ }^{\mathrm{b}}$ Institute of Zoology, Regent's Park, London NW1 4RY, UK \\ ${ }^{\mathrm{c}}$ Boyd Orr Centre for Population and Ecosystem Health, Faculty of Biomedical and Life Sciences, University of Glasgow G12 8QQ UK
}

\section{A R T I C L E I N F O}

\section{Article history:}

Received 18 September 2010

Received in revised form 23 March 2011

Accepted 28 March 2011

Available online 8 May 2011

\section{Keywords:}

African wild dog

Rabies

Canine distemper virus

Vaccination

Epidemiological model

\begin{abstract}
A B S T R A C T
Pathogens such as rabies virus and canine distemper virus present a significant risk to the long-term survival of some endangered African wild dog (Lycaon pictus) populations. Vaccination of wild dogs is one approach that might reduce population extinction risks; however clear guidelines for how best to do this are lacking. Hence, we developed a mathematical model of wild dog population dynamics that integrates a pathogen transmission model and a vaccination process. Simulations indicated that the most effective vaccination strategy includes all age classes (when pups are 2-months old), prioritizes the breeding pair, and vaccinates at least 4 animals per pack included in the vaccination effort. In addition, populations for which an Allee effect, high rates of pathogen introduction, or low rates of recovery and immunity were simulated, required greater vaccination coverage (dogs/pack), to protect an equivalent number of packs compared to populations for which no Allee effect, low rates of pathogen introduction, or high rates of recovery and immunity were simulated. For populations in which some packs (high-risk) have a greater risk of pathogen exposure than others (low-risk), vaccinating both high- and low-risk packs, or only lowrisk packs, is more effective than vaccinating only high-risk packs when pathogen introduction rates are high. Finally, model results suggest that vaccination of wild dog populations against pathogens, such as canine distemper virus, that do not cause 100\% mortality and against which some wild dogs develop acquired immunity, may be unnecessary.
\end{abstract}

(c) 2011 Elsevier Ltd. All rights reserved.

\section{Introduction}

The African wild dog (Lycaon pictus) is one of the world's most endangered carnivores with fewer than 8000 individuals, in fewer than 800 packs, remaining in the wild (summarized in KWS, 2010). Habitat loss and persecution are the major threats to wild dog conservation (Woodroffe et al., 2007), with many wild populations reduced to such small numbers that pathogens such as rabies virus and canine distemper virus (CDV) may pose a significant risk to their long-term persistence (Woodroffe et al., 1997). Hence, strategies for wild dog conservation call for management to reduce this risk (IUCN/SSC, 2007, 2008).

African wild dog populations occur at low densities and it is unlikely that they are capable of maintaining pathogens such as CDV and rabies in the absence of other host species. Although transmission rates within-packs are high, contact between packs is relatively infrequent, such that all animals within a pack may recover or die before they transmit infection to another pack (Mills, 1993; Woodroffe and Donnelly, in preparation). However, these viruses can be introduced through spillover from more

\footnotetext{
* Corresponding author. Tel.: +1 530752 4167; fax: +1 5307523318 .

E-mail address: kcprager@ucdavis.edu (K.C. Prager).
}

abundant maintenance or reservoir hosts, such as domestic dogs (Canis familiaris). In principle, the risk that these pathogens pose to wild dog populations might be reduced either by preventing pathogen transmission from a reservoir, or by protecting individual wild dogs through immunization.

Addressing disease risks to wild dogs by managing pathogens in the reservoir is appealing because it avoids potential risks associated with handling an endangered species. However, several factors complicate this approach. First, there is uncertainty about which species are the reservoir host(s). In most of Africa, evidence suggests that domestic dogs are the principle reservoir responsible for the persistence of rabies (Lembo et al., 2008) and CDV (Alexander et al., 1996; Cleaveland et al., 2000; Gowtage-Sequeira et al., 2009); however, wild carnivore populations may also play a role in pathogen transmission dynamics (Craft et al., 2008; Pfukenyi et al., 2009; Prager et al., in preparation; Sabeta et al., 2007; Zulu et al., 2009). Second, wild dogs' low population densities and wide-ranging behaviour mean that any management of reservoir hosts would need to be conducted over vast areas, entailing considerable effort and expense. Third, unless management directed exclusively at reservoir hosts completely eliminates the pathogen, spillover events can still occur and endanger wildlife health. For example, even with a domestic dog rabies vaccination 
program in place, a rabies outbreak occurred in highly endangered Ethiopian wolves (Canis simensis, Randall et al., 2006).

Given the potential difficulties of managing disease in reservoir hosts, it is worth considering vaccination of wild dogs themselves, to reduce the risks of disease-related population extinction. Captive studies suggest that vaccines against CDV and parvovirus are likely protective in wild dogs (van Heerden et al., 2002). In free-ranging wild dogs, administration of a single dose of inactivated rabies vaccine has failed to prevent deaths (Woodroffe, 2001); however, multiple doses appear to be protective (Hofmeyr et al., 2004) and modified live rabies vaccines, delivered orally, prompted a stronger immune response than did inactivated vaccines (Knobel et al., 2003). Hence, protection of free-ranging wild dogs by vaccination appears achievable in principal.

Because spillover events can occur from the pathogen reservoir, the goal of wild dog vaccination is not to eliminate the pathogen from the endangered population, but rather to protect a sufficient number of individuals from disease-related mortality such that population extinction is avoided (Haydon et al., 2002; USFWS, in press; Vial et al., 2006). The costs of conducting vaccination - in terms of funding, logistics, and (potentially) animal welfare - demand a vaccination program that maximizes population viability while minimizing the number of animals vaccinated.

The efficacy of vaccinating wild dogs might be influenced by the choice of individuals to vaccinate. Wild dogs live in cooperatively-breeding packs with the majority of offspring born to a dominant pair (Malcolm and Marten, 1982). Vaccine could be distributed among many animals in few packs, or few animals in many packs; lower reproductive success in smaller packs (component Allee effects: Courchamp and Macdonald, 2001) might influence this tradeoff. Logistics will also play a role: locating packs for vaccination is likely to be a limiting factor, making it easier to implement strategies which involve vaccinating fewer packs. Pups could be included in, or excluded from, vaccination, and dominant animals could be prioritized. In addition, where some packs within a population face a higher risk of pathogen exposure than others (perhaps because they live closer to domestic dogs, such as along a park boundary), vaccination might target higher- and/or lower-risk packs. The choice of delivery method might also affect the effectiveness of a vaccination strategy. Oral vaccines can only be delivered when packs have small pups in a den and thus can be located repeatedly at a predictable site (Knobel et al., 2002). In contrast, vaccination by injection is the most appropriate method outside the denning period. This difference in timing, and the fact that pups must reach adult size to safely dart for vaccination, would influence the age at which pups might be vaccinated.

We sought to identify the most effective vaccination strategy to protect African wild dogs from pathogen-related extinction events. Building on the work of Vial et al. (2006), we used a mathematical model of wild dog demography, with an integrated epidemiological model, to simulate a variety of vaccination scenarios. Specifically, we investigated the responses of wild dog populations, facing a range of pathogen exposure levels, to vaccination of (i) different numbers of animals per pack; (ii) different numbers of packs per population; (iii) pups of varying age; (iv) dominant animals; and (v) high- and/or low-risk packs. We also investigated the impact of Allee effects, and recovery from infection with pathogen-induced immunity, on the outcome of vaccination programs. In contrast to Vial et al. (2006), we measure vaccination benefits as increases in population size, rather than reductions in extinction probability, because untenably small populations may nevertheless have low extinction probabilities over the 20-years time period over which the populations are simulated.

\section{Methods}

The model is an individually-based, age-, sex- and pack-structured demographically stochastic representation of African wild dog population dynamics with an integrated epidemiologic model. The process of disease transmission and natural mortality were modeled with demographic stochasticity in continuous-time, but vaccination, birth, and pack fission and fusion occurred at fixed time points in the year. The model is therefore essentially individually-based. The details of the model structure are summarized below but described fully in Vial et al. (2006). The entire model was coded and run using Borland ${ }^{\circledR}$ Delphi $7^{\mathrm{TM}}$. Except where indicated otherwise, demographic and behavioral parameters (summarized in Box 1) were derived from a field study of wild dogs inhabiting rangelands of northern Kenya (Woodroffe, 2011). A sensitivity analysis of key demographic parameters (age-specific mortality rates and maximum pack size) was performed and is reported in Appendix A (Supplementary electronic material). The demographic processes are:

1. Births: If a dominant pair is present in a pack, one litter is produced on the 60th day of each year, with annual probability $p_{b}=0.95$. The number of newborn pups in each pack is taken from a frequency distribution of litter size, and each pup is designated male or female with equal probability. Immediately before births occur, all animals undergo age-updating: surviving pups from the preceding year become yearlings, and yearlings become adults. The age of first reproduction is set to $\geqslant 2$ years.

2. Deaths: Age-specific annual mortality rates, excluding diseaserelated mortality, are attributed to pups $\left(m_{p}=0.191\right)$, yearlings $\left(m_{y}=0.093\right)$, and adults $\left(m_{a}=0.192\right)$ independent of sex.

3. Within-pack density dependence: If prior to age-updating the number of adults and yearlings exceeds a fixed threshold size $\left(p_{T}=15\right)$, all female yearlings leave the pack as a single sex group (SSG). If the pack still exceeds the threshold, then all male yearlings also leave as an additional SSG. If the total number of SSGs exceeds the maximum number of SSGs allowed (chosen to be 5), additional SSGs are removed from the population.

4. Pack formation: Fusion occurs randomly and annually (on day 60 prior to breeding), between non-sibling SSGs of the opposite sex if the number of packs (excluding SSGs) is below a defined maximum number of packs (10).

Box 1

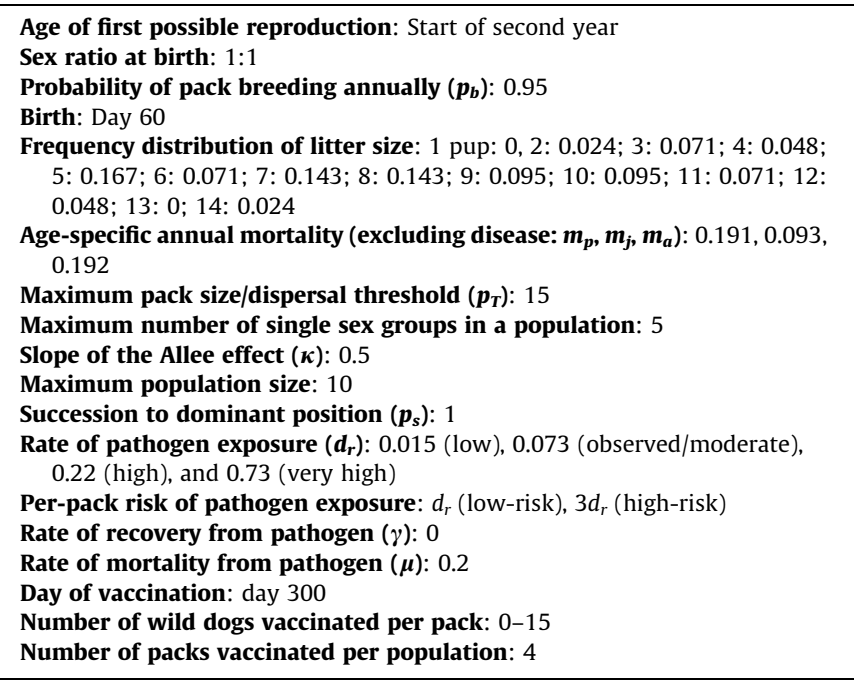


5. Allee effect: When an Allee effect is incorporated, litter size is reduced in smaller packs. For a pack containing $\mathrm{N}$ adult and yearling individuals, litter size is reduced by $\kappa\left(p_{T}-N\right)$, rounded to the nearest integer, and not permitted to become negative. The slope, $\kappa$, was estimated to be 0.5 based on data in Creel et al. (2004) but the effects of increasing this to 0.75 were also explored. is set to zero when the Allee effect is excluded.

6. Succession to dominant position: If, prior to breeding and vaccination, there is no dominant male or female, they may be replaced from within the pack by an adult of the appropriate sex with a probability of $p_{s}$, which equals 1 , except when examining the benefit of prioritizing vaccination of the breeding pair, when it equals 0.3 .

The infectious pathogen processes are as follows:

1. Pathogen exposure: Neither pathogen dynamics in the reservoir, nor the population dynamics of the reservoir itself were modeled explicitly. Pathogen introduction from the reservoir into wild dog packs (containing any susceptible individuals) was modeled as a fixed yearly rate $\left(d_{r}\right)$. This rate has been estimated as 0.073 introduction events/pack/year (once per pack every 13.5 years) in the Kenya study population (RW unpublished data) and 0.083 events/pack/year in northern Botswana (Mills et al., 1998). Analyses were performed at 0.015 (low), 0.073 (moderate), 0.22 (high), and 0.73 (very high) introductions/ pack/year.

2. Per-pack risk of pathogen exposure: We examined vaccination strategies for populations in which all packs had the same risk of exposure and for populations where half of the packs (termed "high-risk packs") were assumed to have a $d_{r}$ three times that of the other packs (termed "low-risk packs").

3. Pathogen dynamics: Once infection was present in a wild dog pack, individuals were subjected to a continuous-time, susceptible-infected-recovered/vaccinated (SIR-V) process (Anderson and May, 1991). The infection rates (both from reservoir to pack and within-pack) were used to compute stochastic orders and times of transfer of individual animals from susceptible to infectious categories according to a conventional Gillespie process (Gillespie, 1976):

$S_{i}(t) \rightarrow S_{i}(t)-1=I_{i}(t) \rightarrow I_{i}(t)+1=\beta S_{i}(t) I_{i}(t)$

$I_{i}(t) \rightarrow I_{i}(t)-1=R_{i}(t) \rightarrow R_{i}(t)+1=\mu I_{i}(t)+\gamma I_{i}(t)$

$S_{i}(t), I_{i}(t)$ and $R_{i}(t)$ are the numbers of susceptible, infectious and recovered and/or removed individuals in the $i$ th pack at time $t$. Based on mortality and seropositivity data from known or suspected CDV (Alexander and Appel, 1994; Alexander et al., 2010; van de Bildt et al., 2002) and rabies (Hofmeyr et al., 2000, 2004; Kat et al., 1995; Scheepers and Venzke, 1995) outbreaks in wild dogs, $\beta$ was chosen so that on average outbreaks led to infection in $90 \%$ of pack members. The rate of recovery from the pathogen with life-long immunity is $\gamma$, and the rate of mortality from the pathogen is $\mu$. The sum of $\gamma$ and $\mu$ is set to 0.2 , corresponding to a 5 days infectious period. When all wild dogs exposed to rabies were assumed to die, $\gamma$ was set to 0 and $\mu$ was set to 0.2 ; when $5 \%$ of dogs were assumed to recover with immunity, $\gamma$ was set to 0.01 and $\mu$ to 0.19 . When simulating CDV dynamics $\gamma$ was set to 0.04 or 0.1 , and $\mu$ was set to 0.16 or 0.1 , corresponding to $20 \%$ or $50 \%$ of dogs recovering with immunity.

Vaccination strategies were designed to maintain a fixed number of vaccinally protected wild dogs in each of a predetermined number of packs. Vaccination took place on day 120 or 300, corresponding to dates when pups are 2-months old and could consume oral vaccine at the den, or 8-months old and just large enough to safely dart and vaccinate parenterally. Vaccine-induced immunity was assumed to persist for 2 years.

Pathogen introduction and mortality were run as continuous stochastic processes. Breeding, vaccination, succession to dominance, and pack fusion and fission were fixed-time annual events (see Figs. B.1. and B.2. in Appendix B of the Supplementary electronic material for flow diagrams of the model).

We investigated each of the following scenarios, varying the number of animals vaccinated per pack in each case:

1. Vaccination of varying numbers of packs (1-10) in a population of a fixed maximum size, initially comprising 10-packs.

2. Vaccination of all age groups when pups are either 2- or 8months old, versus vaccinating just adults and yearlings (i.e., excluding pups), versus vaccinating just pups.

3. Prioritizing vaccination of the dominant pair.

4. Vaccination against pathogens from which $0-50 \%$ of exposed/ infected individuals recover and develop life-long immunity.

5. Vaccination of a population exhibiting a component Allee effect.

6. Vaccination distributed among packs experiencing different levels of pathogen exposure, targeting only low-risk, only high-risk, or a mixture of high- and low-risk packs.

We measured the effectiveness of vaccination strategies as the numbers of packs remaining after 20 years. This measure was more informative than extinction probability because, for some parameter values, simulations predicted substantial population decline but low probabilities of extinction within the 20-years simulation. As there were stochastic processes in the model, we ran 1000 simulations for each scenario and reported the average result. Unless otherwise stated, default values were: initial population size of 10 low-risk packs, vaccination of all ages including pups aged 8months, no prioritization of the dominant pair, no acquired immunity, and no Allee effect. Packs were initiated with 16 individuals as follows: one dominant adult male, one dominant adult female, five non-dominant males, two non-dominant females, three yearling males and four yearling females.

\section{Results}

For all simulations, as $d_{r}$ - the rate of pathogen introduction decreased, final population size increased. At the lowest $d_{r}$ examined, few vaccinated animals were needed for a population to maintain its original size (Fig. 1a). Sensitivity analyses indicated that the major findings from the model analyses were qualitatively robust to plausible variation in age-specific mortality and maximum pack size, although minor quantitative differences existed; full results are detailed in Appendix A (Supplementary electronic material: Figs. A1-A12).

\subsection{Number of packs vaccinated}

We evaluated the effect of varying the number of packs vaccinated in a 10-pack population. For all values of $d_{r}$, final population size was greater as more packs were vaccinated (Fig. 1a-c); however, at the low $d_{r}$ there was little difference in the number of packs remaining with 0 versus 10-packs vaccinated (Fig. 1a). In addition, for all $d_{r}$ the benefit of vaccinating additional packs decreased as the number of packs vaccinated approached $100 \%$. At both moderate and high $d_{r}$, all but the highest levels of coverage failed to prevent the population from declining during the 20-years simulation (Fig. 1b and 1c). Simulations also indicated that vaccinating few individuals in many packs was more effective than vaccinating many individuals in few packs and there was little benefit to vaccinating more than 4 dogs/pack (Fig. 1b). For example, at moderate 

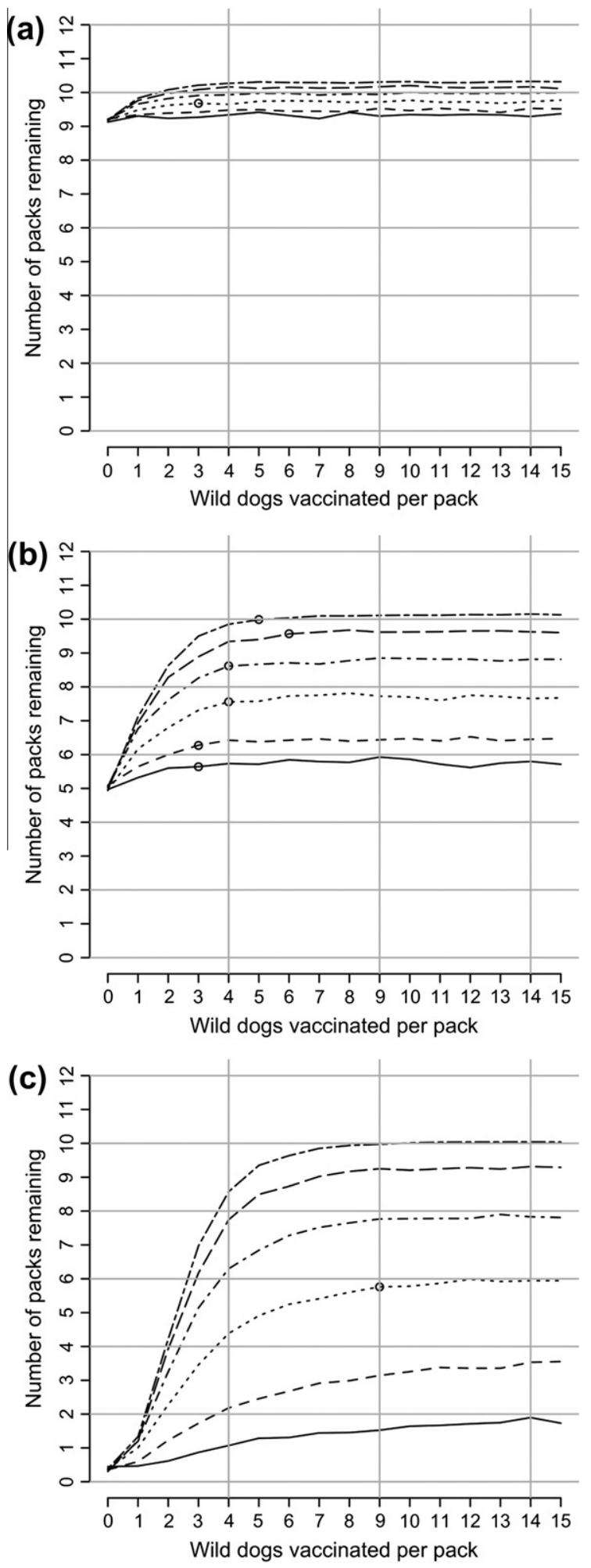

\begin{tabular}{|cccc|}
\hline \multicolumn{3}{|c|}{ Number of Packs Vaccinated } \\
- & 1 Pack & -- & 6 Packs \\
-- & 2 Packs & -- & 8 Packs \\
$\cdots-$ & 4 Packs & --- & 10 Packs \\
\hline
\end{tabular}

Fig. 1. The effect of including different numbers of packs $(1,2,4,6,8$ and 10$)$ in the vaccination effort. The point on each line that corresponds to 0 wild dogs vaccinated represents the outcome of a strategy where no packs or animals are vaccinated. The value of $d_{r}$ increases from low (a), to moderate (b), to high (c). Hollow circles in (ac) represent the number of wild dogs required to be vaccinated per pack that achieved a final population size $\leqslant 0.2$ packs less than the size achieved when the maximum individuals/pack (15) were vaccinated.
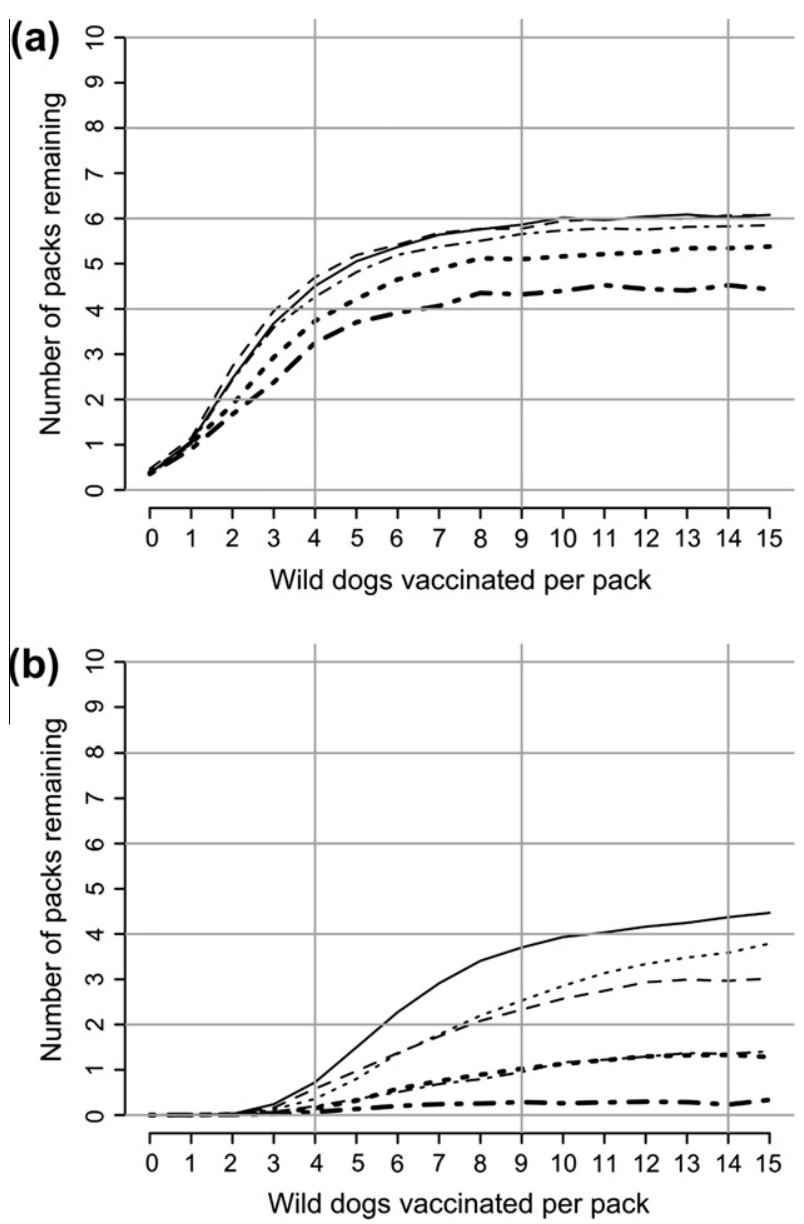

$$
\begin{gathered}
\text { Ages Vaccinated \& Vaccination Day } \\
\text { - All ages: day } 120 \\
\ldots-\text { All ages: day } 300 \\
\text { - Pups excluded: day } 120 \\
\text {-- Pups excluded: day } 300 \\
\text { - Pups only: day } 120 \\
\hline- \text { Pups only: day } 300
\end{gathered}
$$

Fig. 2. The effect of excluding different age groups from vaccination efforts and of vaccinating at different times of year. The $d_{r}$ increases from high (a) to very high (b).

$d_{r}$, vaccinating two wild dogs in eight packs resulted in a final population of $\sim 8$ packs after 20 years, whereas vaccinating either four or eight wild dogs in two packs resulted in a final population of only $\sim 6$ packs after 20 years.

\subsection{Age of vaccination}

We evaluated the benefit of vaccinating all age groups when pups were 2- or 8-months old, of vaccinating only pups, and of excluding pups entirely. Simulations showed that at low, medium and high $d_{r}$ (Fig. 2a), fewer packs remained when only pups were vaccinated but that strategies targeting all ages, or just adults and yearlings, differed little in outcome. At very high $d_{r}$, targeting all age classes when pups were 2-months old, resulted in more packs remaining than the other strategies (Fig. $2 \mathrm{~b}$ ).

\subsection{Prioritizing the dominant pair}

Prioritizing the dominant pair for vaccination did not substantially increase the number of packs persisting at low or moderate $d_{r}$ (Fig. 3a). However, up to twice as many packs persisted at high $d_{r}$ (Fig. 3b). 

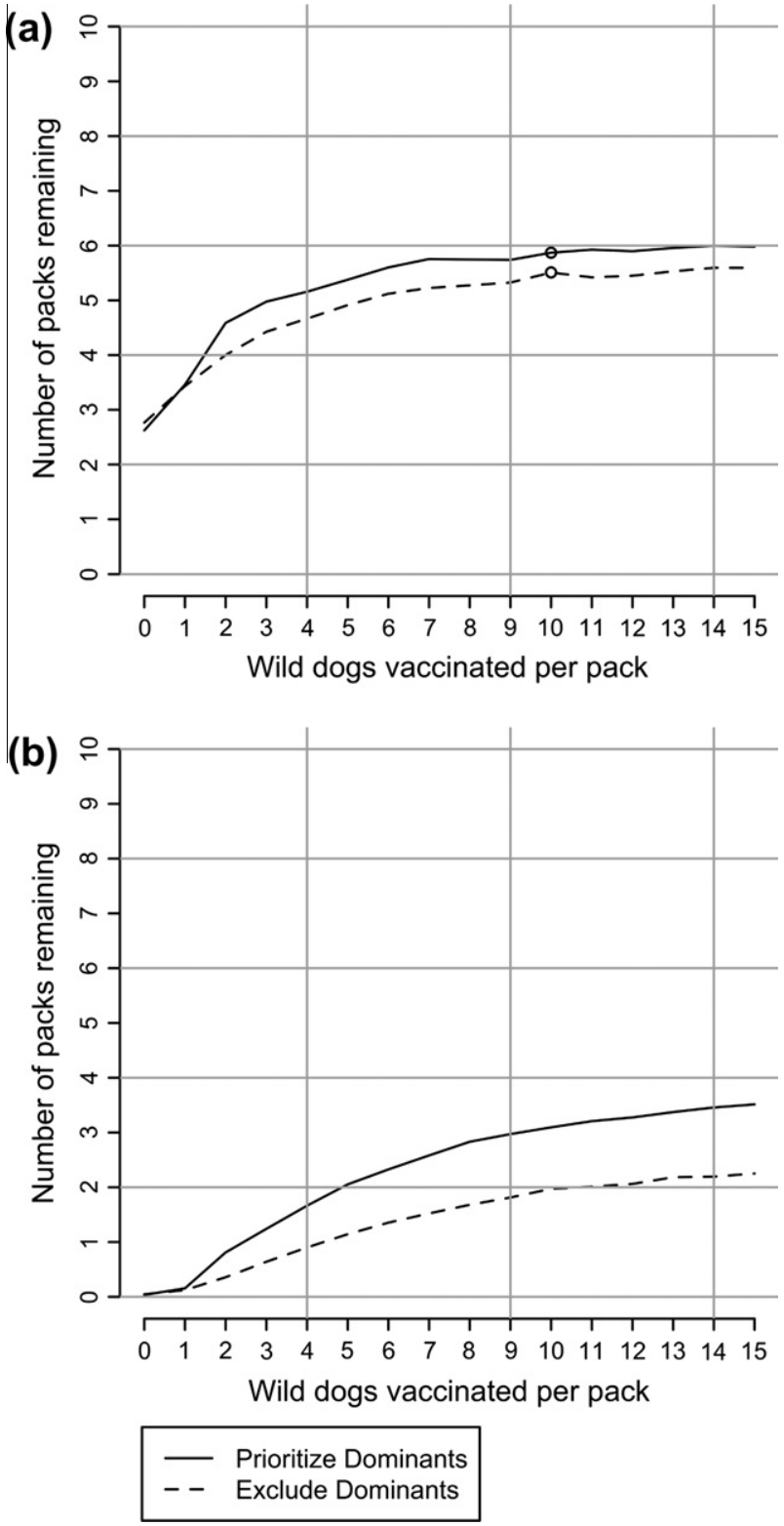

Fig. 3. Effects of including or excluding the dominant pair in the vaccination effort: evaluated at moderate (a) and high (b) rates of $d_{r}$. Position of hollow circles as described in Fig. 1.

\subsection{Recovery and immunity}

Acquired immunity to the pathogen markedly improved simulated populations' ability to maintain their size in the face of pathogen introduction, and reduced the level of vaccination coverage required to maintain population size. At equivalent vaccination levels, if even as few as $5 \%$ of infected wild dogs survived and developed immunity, substantially more packs persisted than if the pathogen caused $100 \%$ mortality (Fig. $4 \mathrm{a}$ and $4 \mathrm{~b}$ ). At high $d_{\mathrm{r}}$ and no vaccination coverage, if $\geqslant 20 \%$ of infected individuals developed immunity, the final population size approached that of a pathogen-free population, and equaled it when $\geqslant 50 \%$ developed immunity (Fig. 4b).

\subsection{Allee effect}

Incorporating an Allee effect decreased the number of packs remaining (Fig. 5a and $b$ ) and reduced the average size of remain-
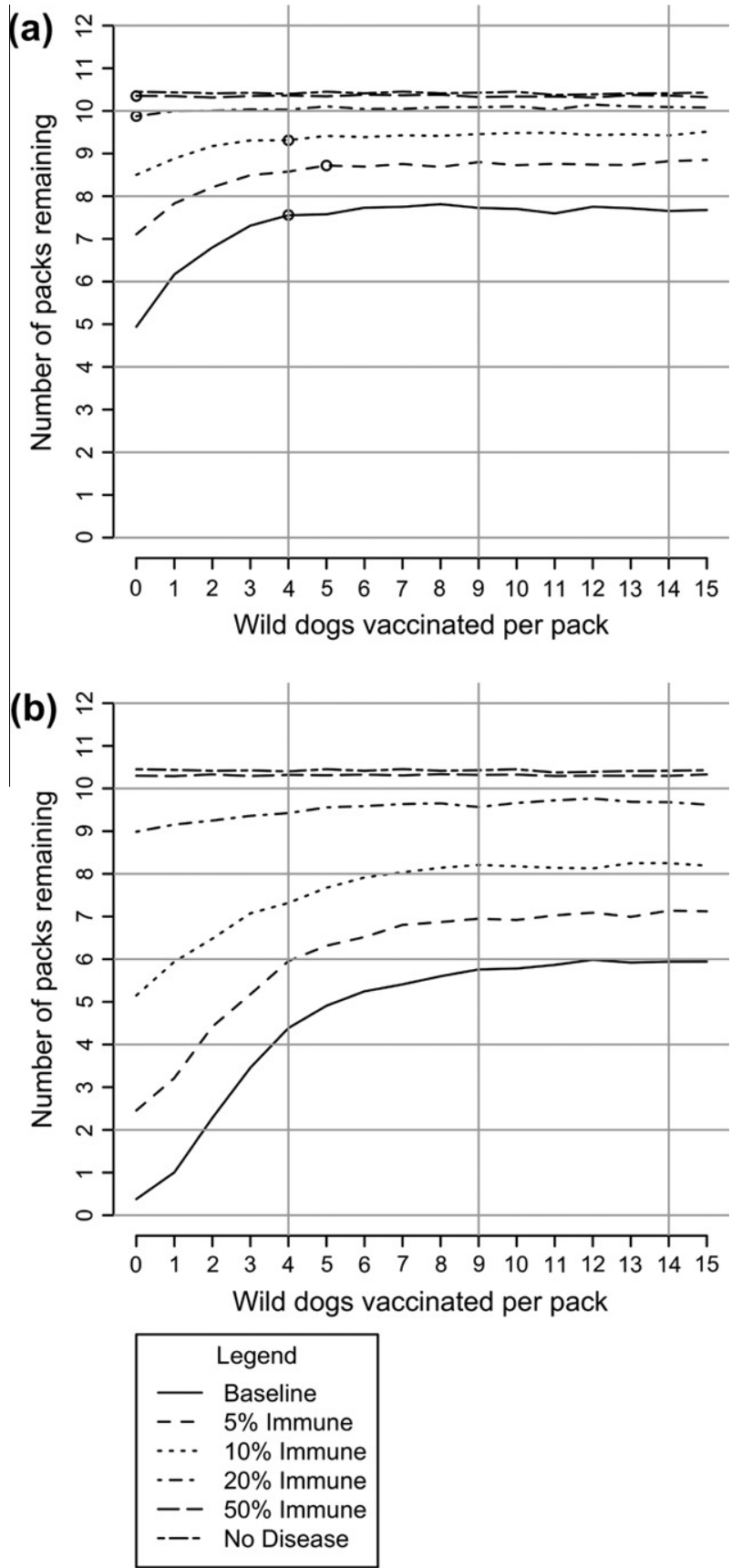

Fig. 4. Impacts of acquired immunity ( $0-50 \%$ of exposed dogs) on the effectiveness of a vaccination strategy targeted at a population experiencing moderate (a) and high (b) $d_{r}$. A population experiencing no pathogen exposure is included for reference ("No Disease"). Position of hollow circles as described in Fig. 1.

ing packs (Fig. $5 \mathrm{c}$ and $\mathrm{d}$ ) for a given level of vaccination. The magnitude of this effect was much smaller at low values of $d_{r}$ and Allee slope. At low $d_{r}$, there was little difference in numbers of packs remaining between simulations assuming no Allee effect and those assuming an Allee effect with a slope of 0.5. The difference in packs remaining between populations with and without Allee effects decreased, and average pack size increased, at high levels of per-pack vaccination coverage.

\subsection{Risk of pathogen exposure}

Since wild dog populations may contain some "high-risk packs" with a greater risk of pathogen exposure than "low-risk packs", we 

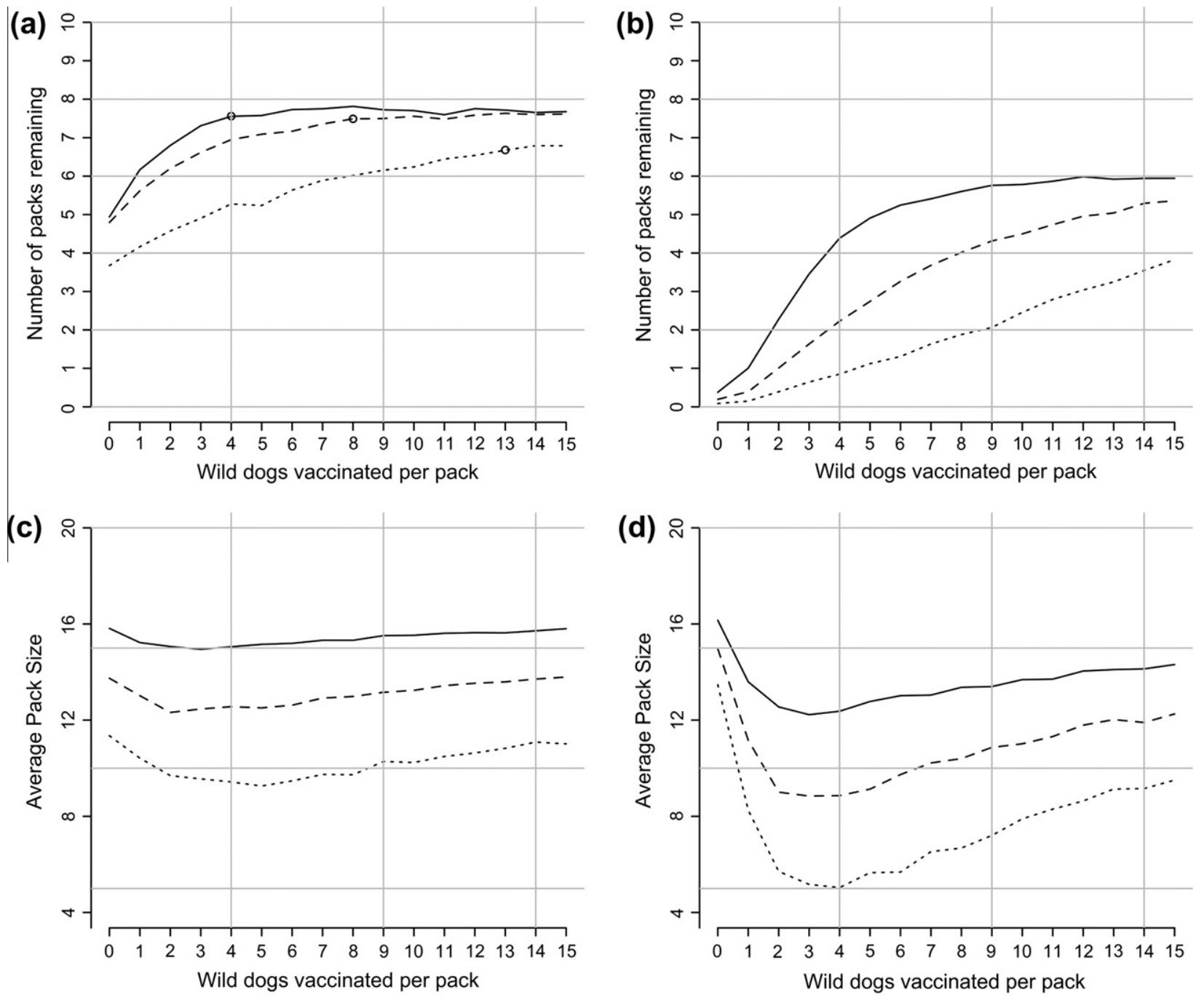

$$
\begin{array}{|cc|}
\hline \text { Degree of Allee Slope }(\mathrm{k}) \\
-\quad \mathrm{k}=0 \\
-- & \mathrm{k}=0.5 \\
\cdots & \mathrm{k}=0.75
\end{array}
$$

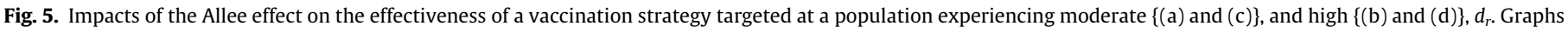
show the number of packs remaining $\{(\mathrm{a})$ and $(\mathrm{b})\}$ and the average pack size in the population $\{(\mathrm{c})$ and (d)\}. Position of hollow circles as described in Fig. 1 .

compared vaccination strategies which targeted only high-risk packs, only low-risk packs, or both high- and low-risk packs with equal probability. We found that as $d_{r}$ increased, the strategy that imparted the greatest relative benefit changed. At low and moderate $d_{r}$ (Fig. 6a) more packs remained when only high-risk packs were vaccinated, but the difference between each of the three strategies was slight. At high $d_{r}$, up to three times more packs remained when either a mixture of both high- and low-risk packs, or just low-risk packs were vaccinated, versus vaccinating only high-risk packs (Fig. 6b: vaccination coverage three per pack).

\subsection{Diminishing returns}

The number of packs persisting over the 20-years simulation increased as more dogs were vaccinated per pack but the benefits diminished with increasing coverage. We identified the number of wild dogs required to be vaccinated per pack that achieved a final population size $\leqslant 0.2$ packs less than the size achieved when the maximum individuals/pack (15) were vaccinated. This number increased as $d_{r}$ increased (Fig. 1a-c). In addition, at moderate $d_{r}$, this number increased (i) as more packs were included in the vaccination effort (Fig. 1b); (ii) as the percent of individuals in which the pathogen induces immunity decreased (Fig. 4a); and (iii) in the presence of an Allee effect (Fig. 5a). Prioritizing the dominant pair did not change this number (Fig. 3a). Excluding simulations in which populations experienced a successional probability of $<1$, in which a pathogen could induce $>20 \%$ protective immunity, and which evaluated an Allee effect with a slope $>0.5$, this number at moderate $d_{r}$ varied between 3 and 8 (Figs. 1b, 4a and 5a).

\section{Discussion}

Our simulations suggest that, in principle, vaccination could conserve African wild dog populations' size and persistence in the face of observed rates of pathogen exposure $\left(d_{r}\right)$ and that certain vaccination strategies would be more effective than others. For example, the effectiveness of the strategy would depend on the number of vaccinated dogs per pack and vaccinated packs 

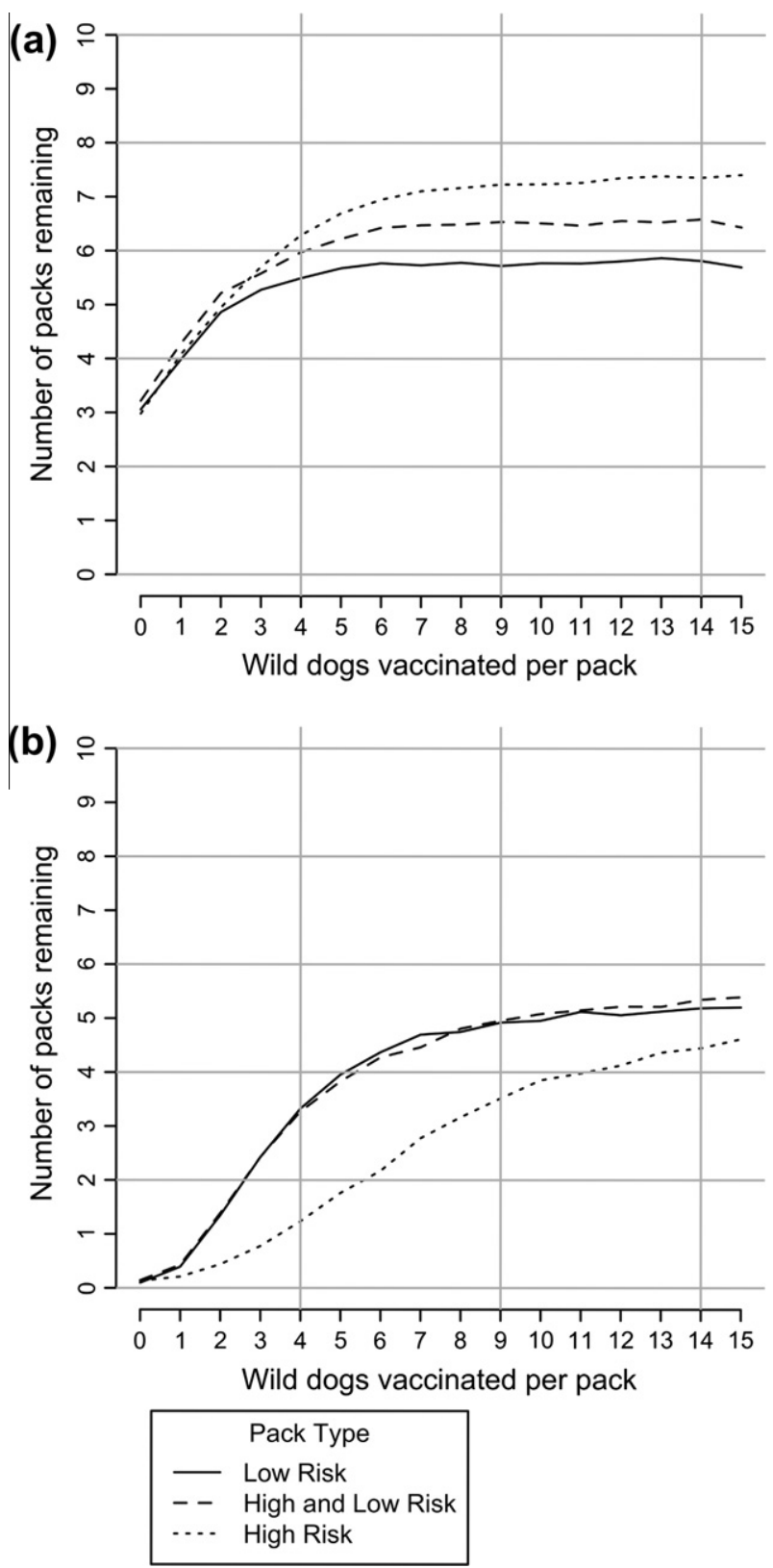

Fig. 6. Evaluation of vaccination strategies targeting only high-risk, only low-risk, or equivalent numbers of high- and low-risk packs. Graphs show effects in populations experiencing moderate (a) and high (b) $d_{r}$.

per population, as well as on the age and social status of the individuals vaccinated.

Our simulations showed that little or no vaccination was needed to maintain population size at low $d_{r}$. Where $d_{r}$ is high, reducing infection levels in the reservoir is one potential way to decrease transmission to wild dogs, thereby reducing or removing the need for wild dog vaccination. Cleaveland et al. (2003) described a domestic dog vaccination campaign in rural Tanzania that reduced the incidence of domestic dog rabies by $97 \%$. If this reduction prompted an equivalent decline in $d_{r}$ to wild dogs, it would reduce the observed $d_{r}$ of $0.073 /$ pack/year to $0.002 /$ pack/ year, a rate so low that wild dog vaccination would likely be unnecessary. Hence domestic dog vaccination against rabies could benefit wild dogs, in addition to reducing rabies incidence in humans. However to be effective, such domestic dog vaccination would need to be maintained yearly over potentially large spatial scales.
For example, a domestic dog vaccination campaign in rural Ethiopia failed to prevent a rabies outbreak in Ethiopian wolf populations within the vaccination zone because of high yearly turnover and growth in the domestic dog population, and frequent movement of dogs into both the vaccination zone and wolf habitat (Randall et al., 2006).

Wild dog vaccination was likewise not required if the pathogen induced protective immunity in $\geqslant 20 \%$ of infected individuals. The protective immunity induced by exposure is equivalent or superior to that achieved through vaccination; thus provided mortality does not exceed $80 \%$, vaccination against pathogens such as CDV and canine parvovirus would probably not be warranted. However, CDV mortality appears to vary widely among wild dogs and in some cases may exceed $80 \%$ (Alexander and Appel, 1994; Alexander et al., 1996; van de Bildt et al., 2002). Thus, CDV vaccination may be required in certain situations and may be an important consideration for very small wild dog populations. Anti-rabies antibodies have been found in unvaccinated wild dogs (Gascoyne et al., 1993; Prager et al., in preparation). If these antibodies provide acquired immunity $(\geqslant 5 \%)$, simulations indicate that the vaccine coverage needed to protect wild dog populations from extinction is reduced, often substantially, relative to simulations in which acquired immunity is absent.

At high $d_{r}$, vaccination strategies directed at the dominant pair, and including pups as young as 2-months old, provided the greatest benefit. However, such benefits were not detectable at the moderate $d_{r}$ derived from empirical data. Nevertheless, as the $d_{r}$ experienced by many populations is unknown, where possible prioritization of dominants and inclusion of pups would be prudent.

Population size was conserved to a greater extent as more packs were included in the vaccination effort. Our results suggest that if the number of vaccinations to distribute in the population is fixed, the most effective, though likely more logistically challenging, strategy maximizes the number of packs included in the vaccination effort rather than the number of individuals vaccinated per pack. We also found that above a certain number, the benefit of vaccinating additional animals was minimal. At moderate $d_{r}$, vaccinating more than 4-5 wild dogs, per pack (mean wild dog pack size reported for several populations varies between 8 and 12 adults and yearlings (summarized in Woodroffe, 2011)), offered little added benefit, although this number was greater with the Allee effect and at $d_{r}$ values greater than that found in our reference populations.

The relative risk of pathogen exposure experienced by the different packs in a population influenced the most effective vaccination strategy. For populations experiencing moderate $d_{r}$, vaccinating only high-risk packs provided the greatest benefit; however this benefit was marginal. For populations experiencing high overall $d_{r}$ and containing packs experiencing different levels of pathogen exposure, vaccinating both high- and low-risk packs, or just low-risk packs, provided the greatest benefit. Hence, in case $d_{r}$ is greater than that estimated from our reference populations, vaccinating both high- and low-risk packs may be advisable. We conjecture that this switch in the relative benefit of the different strategies as $d_{r}$ increases is due to a "source/sink" process. At low and moderate $d_{r}$, vaccinated high-risk packs act as a "source" of wild dogs to unvaccinated low-risk "sink" packs that experience higher disease-related mortality. However, at very high $d_{r}$ even the highest levels of vaccination coverage of highrisk packs fail to prevent deaths of pups too young to vaccinate parenterally; hence, when vaccinated adults die, they cannot be replaced. Therefore vaccinated low-risk packs, for which $d_{r}$ are lower and pups are able to survive to vaccination, are needed as the "source" to the high-risk pack "sink". 


\section{Conclusion}

Our simulations allow tentative recommendations to improve persistence of African wild dog populations exposed to pathogens such as rabies and CDV. Highly infectious pathogens that may cause $95-100 \%$ mortality within-packs, such as rabies, can present an important risk to wild dog population numbers and persistence. For the levels of exposure to such pathogens reported from wild dog study populations, the most effective vaccination strategy would target all age classes, prioritize dominant individuals, and include at least four individuals per pack in as many packs as possible. For pathogens causing lower mortality, such as CDV, acquired immunity may allow wild dog populations to persist and maintain their size without vaccination even in the face of high exposure rates. Finally, if rabies exposure in wild dog populations could be permanently reduced by domestic dog vaccination over the very large spatial scales covered by wild dog home ranges, the need for wild dog vaccination might be reduced or eliminated, thus reducing the degree of intervention needed to prevent devastating wild dog population reductions due to infectious disease.

\section{Acknowledgements}

The Morris Animal Foundation provided funding to K.P. and R.W.; and the BBSRC provided funding to A.C.; however, they had no role in study design, collection and analysis and interpretation of data, in the writing of the report; and in the decision to submit the paper for publication. The authors would like to thank three anonymous reviewers for their helpful comments and suggestions.

\section{Appendix A. Supplementary material}

Supplementary data associated with this article can be found, in the online version, at doi:10.1016/j.biocon.2011.03.025.

\section{References}

Alexander, K.A., Appel, M.J.G., 1994. African wild dogs (Lycaon pictus) endangered by a canine distemper epizootic among domestic dogs near the Masai Mara National Reserve, Kenya. Journal of Wildlife Diseases 30, 481-485.

Alexander, K.A., Kat, P.W., Munson, L.A., Kalake, A., Appel, M.J.G., 1996. Canine distemper-related mortality among wild dogs (Lycaon pictus) in Chobe National Park, Botswana. Journal of Zoo and Wildlife Medicine 27, 426427.

Alexander, K.A., McNutt, J.W., Briggs, M.B., Standers, P.E., Funston, P., Hemson, G., Keet, D., van Vuuren, M., 2010. Multi-host pathogens and carnivore management in southern Africa. Comparative Immunology, Microbiology and Infectious Diseases 33, 249-265.

Anderson, R.M., May, R.M., 1991. Infectious Diseases of Humans: Dynamics and Control. Oxford University Press, Oxford.

Cleaveland, S., Appel, M.G.J., Chalmers, W.S.K., Chillingworth, C., Kaare, M., Dye, C., 2000. Serological and demographic evidence for domestic dogs as a source of canine distemper virus infection for Serengeti wildlife. Veterinary Microbiology 72, 217-227.

Cleaveland, S., Kaare, M., Tiringa, P., Mlengeya, T., Barrat, J., 2003. A dog rabies vaccination campaign in rural Africa: impact on the incidence of dog rabies and human dog-bite injuries. Vaccine 21, 1965-1973.

Courchamp, F., Macdonald, D.W., 2001. Crucial importance of pack size in the African wild dog Lycaon pictus. Animal Conservation 4, 169-174.

Craft, M.E., Hawthorne, P.L., Packer, C., Dobson, A.P., 2008. Dynamics of a multihost pathogen in a carnivore community. Journal of Animal Ecology 77, 1257-1264.

Creel, S., Mills, M.G.L., McNutt, J.W., 2004. Demography and population dynamics of African wild dogs in three critical populations. In: Macdonald, D.W., SilleroZubiri, C. (Eds.), The Biology and Conservation of Wild Canids. Oxford University Press, Oxford.

Gascoyne, S.C., Laurenson, M.K., Lelo, S., Borner, M., 1993. Rabies in African wild dogs (Lycaon pictus) in the Serengeti region, Tanzania. Journal of Wildlife Diseases 29, 396-402.
Gillespie, D.T., 1976. A general method for numerically simulating the stochastic time evolution of coupled chemical reactions. Journal of Computational Physics $22,403-434$.

Gowtage-Sequeira, S., Banyard, A.C., Barrett, T., Buczkowski, H., Funk, S.M., Cleaveland, S., 2009. Epidemiology, pathology, and genetic analysis of a canine disetemper epidemic in Namibia. Journal of Wildlife Diseases 45 , 1008-1020.

Haydon, D.T., Laurenson, M.K., Sillero-Zubiri, C., 2002. Integrating epidemiology into population viability analysis: managing the risk posed by rabies and canine distemper to the Ethiopian wolf. Conservation Biology 16, 13721385.

Hofmeyr, M., Bingham, J., Lane, E.P., Ide, A., Nel, L., 2000. Rabies in African wild dogs (Lycaon pictus) in the Madikwe Game Reserve, South Africa. Veterinary Record 146, 50-52.

Hofmeyr, M., Hofmeyr, D., Nel, L., Bingham, J., 2004. A second outbreak of rabies in African wild dogs (Lycaon pictus) in Madikwe Game Reserve, South Africa, demonstrating the efficacy of vaccination against natural rabies challenge. Animal Conservation 7, 193-198.

IUCN/SSC, 2007. Regional Conservation Strategy for the Cheetah and African Wild Dog in Southern Africa. I.S.S. Commission, Gland, Switzerland.

IUCN/SSC, 2008. Regional Conservation Strategy for the Cheetah and Wild Dog in Eastern Africa. I.S.S. Commission, Gland, Switzerland.

Kat, P.W., Alexander, K.A., Smith, J.S., Munson, L., 1995. Rabies and African wild dogs in Kenya. Proceedings of the Royal Society of London Series B - Biological Sciences 262, 229-233.

Knobel, D.L., du Toit, J.T., Bingham, J., 2002. Development of a bait and baiting system for delivery of oral rabies vaccine to free-ranging African wild dogs (Lycaon pictus). Journal of Wildlife Diseases 38, 352-362.

Knobel, D.L., Liebenberg, A., Du Toit, J.T., 2003. Seroconversion in captive African wild dogs (Lycaon pictus) following administration of a chicken head bait/SAG-2 oral rabies vaccine combination. Onderstepoort Journal of Veterinary Research 70, 73-77.

KWS, 2010. Proposal for Inclusion of Species on the Appendices of the Convention of the Conservation of Migratory Species of Wild Animals. Kenya Wildlife Service, Nairobi, Kenya. <http://www.cms.int/bodies/COP/cop9/proposals/Eng/ II_5_Lycaon_pictus_KEN_E.pdf $>$.

Lembo, T., Hampson, K., Haydon, D.T., Craft, M., Dobson, A., Dushoff, J., Ernest, E., Hoare, R., Kaare, M., Mlengeya, T., Mentzel, C., Cleaveland, S., 2008. Exploring reservoir dynamics: a case study of rabies in the Serengeti ecosystem. Journal of Applied Ecology 45, 1246-1257.

Malcolm, J.R., Marten, K., 1982. Natural selection and the communal rearing of pups in African wild dogs (Lycaon pictus). Behavioral Ecology and Sociobiology 10, 113.

Mills, M.G.L., 1993. Social systems and behavior of the African wild dog Lycaon pictus and the spotted hyena Crocuta crocuta with special reference to rabies. Onderstepoort Journal of Veterinary Research 60, 405-409.

Mills, M.G.L., Ellis, S., Woodroffe, R., Maddock, A., Stander, P., Rasmussen, G., Pole, A., Fletcher, P., Bruford, M., Wildt, D., Macdonald, D.W., Seal, U.S., 1998. Population and habitat viability assessment for the African wild dog (Lycaon pictus) in southern Africa. In: IUCN/SSC Conservation Breeding Specialist Group. IUCN/ SSC, Apple Valley, MN.

Pfukenyi, D.M., Pawandiwa, D., Makaya, P.V., Ushewokunze-Obatolu, U., 2009. A retrospective study of wildlife rabies in Zimbabwe, between 1992 and 2003. Tropical Animal Health and Production 41, 565-572.

Prager, K.C., Mazet, J.A.K., Dubovi, E.J., Frank, L., Munson, L., Wagner, A.P., Woodroffe, R., in preparation. Rabies virus and canine distemper virus in wild and domestic carnivores in Northern Kenya: are domestic dogs the reservoir? Ecohealth.

Randall, D.A., Marino, J., Haydon, D.T., Sillero-Zubiri, C., Knobel, D.L., Tallents, L.A., Macdonald, D.W., Laurenson, M.K., 2006. An integrated disease management strategy for the control of rabies in Ethiopian wolves. Biological Conservation $131,151-162$

Sabeta, C.T., Mansfield, K.L., McElhinney, L.M., Fooks, A.R., Nel, L.H., 2007. Molecular epidemiology of rabies in bat-eared foxes (Otocyon megalotis) in South Africa. Virus Research 129, 1-10.

Scheepers, J.L., Venzke, K.A.E., 1995. Attempts to reintroduce African wild dogs Lycaon pictus into Etosha National Park, Namibia. South African Journal of Wildlife Research 25, 138-140.

USFWS, in press. Recovery Plan for the Island Fox. US Fish \& Wildlife Service, Ventura.

van de Bildt, M.W.G., Kuiken, T., Visee, A.M., Lema, S., Fitzjohn, T.R., Osterhaus, A., 2002. Distemper outbreak and its effect on African wild dog conservation. Emerging Infectious Diseases 8, 211-213.

van Heerden, J., Bingham, J., van Vuuren, M., Burroughs, R.E.J., Stylianides, E., 2002. Clinical and serological response of wild dogs (Lycaon pictus) to vaccination against canine distemper, canine parvovirus infection and rabies. Journal of the South African Veterinary Association-Tydskrif Van Die Suid-Afrikaanse Veterinere Vereniging 73, 8-12.

Vial, F., Cleaveland, S., Rasmussen, G., Haydon, D.T., 2006. Development of vaccination strategies for the management of rabies in African wild dogs. Biological Conservation 131, 180-192.

Woodroffe, R., 2001. Assessing the risks of intervention: immobilization, radio-collaring and vaccination of African wild dogs. Oryx 35, 234244.

Woodroffe, R., 2011. Demography of a recovering African wild dog (Lycaon pictus) population. Journal of Mammalogy 92, 305-315. 
Woodroffe, R., Donnelly, C., in preparation. Risk of contact between endangered African wild dogs Lycaon pictus and domestic dogs: opportunities for pathogen transmission. Journal of Applied Ecology.

Woodroffe, R., Ginsberg, J.R., Macdonald, D.W., 1997. The African Wild Dog: Status Survey and Conservation Action Plan. IUCN, Gland.

Woodroffe, R., Davies-Mostert, H., Ginsberg, J., Graf, J., Leigh, K., McCreery, K., Mills, G., Pole, A., Rasmussen, G., Robbins, R., Somers, M., Szykman, M., 2007. Rates and causes of mortality in endangered African wild dogs Lycaon pictus: lessons for management and monitoring. Oryx 41, 215-223.

Zulu, G.C., Sabeta, C.T., Nel, L.H., 2009. Molecular epidemiology of rabies: focus on domestic dogs (Canis familiaris) and black-backed jackals (Canis mesomelas) from northern South Africa. Virus Research 140, 71-78. 